\title{
Using a method of measuring the state of biodiversity in cities, using the index (CBI) in Tehran: A strategy for urban management
}

\author{
Dr. Anita REYHANIAN ${ }^{1}$, Ali Bagherpour PORSHOKOUH ${ }^{*, 2}$ \\ ${ }^{1}$ Institue of Biological Sciences Faculty of Science University of Malaya. \\ ${ }^{2}$ Department of Environmental Science, Islamic Azad University, Science and Research Branch, \\ Tehran, Iran.
}

\begin{abstract}
Biodiversity is seriously affected by the construction and development of the city as well. Open unbridled urbanization has been accompanied by the destruction of natural ecosystems and unfortunately resulted in the loss of native species in the region. On the other hand, due to the human tendency to planting non-native species, ecosystems urban environment is very fragile and in case of problems such as drastic changes in temperature or drought, many species disappear. Restoration of biodiversity in cities, due to the spread of pollution and degradation of habitat quality, integrated management through proper use of technical facilities and appropriate species is adapted to urban environments. Is able to rapidly and quality, ecological services such as air purifiers, create microclimate and protection of water resources, biodiversity, along with the revival as much as possible to bring animals of the region. Because on the one hand Tehran in the Alborz mountains and the desert climate is led and in certain circumstances have potential richness of biodiversity. But due to excessive construction, environmental pollution, using conversion and logging of old trees, climate change and lack of attention to the high value of its massive trove of biodiversity, habitats and destruction in these cities is changing with the change of structure in the city its performance is also affected and many plant and animal species that have been changed and some destruction. In this study, the role of biodiversity in order to protect and restore native biodiversity of an abuse, And proper use of the method of measuring the status of biodiversity using CBI indicators in order to create ecological services, to habitable the other hand will be discussed in Tehran.
\end{abstract}

Key words: biodiversity, the index of CBI, urban management

\section{Problem Statement}

A concept which has three levels of biological diversity in genes, species and ecosystems is considered, but at the level of species and ecosystems are more familiar and more applications. Since the biodiversity of the world's natural capital is, Health is the life of society for various reasons thereof. Quantitative and qualitative criteria in terms of biodiversity, environmental economics, natural capital and the most important indicators of ecological health in all parts of the world. Unfortunately, the man with the foolish use of this wealth can cause its destruction and self-destruction is in fact are. Cities are expanding fast compared to the urban population. Cities area is expected to triple between 2000 and 2030 is expected. While the urban population is expected nearly to double (about 2.84 to 4.9 billion people) will increase. The urban

\footnotetext{
* - Corresponding Author
} 
development on a global scale swayed heavily on natural resources and utilizes most of the agricultural land and the destruction of biodiversity and associated ecosystem. Is expected to be urbanized by 2050 almost 70 percent of the world population. Recent studies show that food supply in the world having almost doubled between 2000 and 2050 to meet the food needs of a growing population. As well as global energy demand may increase to $80 \%$ and also increased water demand is expected to be 55\%. Growing urbanization due to land degradation and pollution of natural resources is one of the most important threats to biodiversity. Although cities cover only 2 percent of the Earth's surface, their inhabitants consume more than 75 percent of natural resources. Cities need resources for their survival and the production of energy from the surrounding environment and pollution are numerous. In addition to land degradation (habitat), resulting in the loss of biodiversity contained in it, with the disappearance of sensitive species native and non-technical and replace them with resistant strains that are often aggressive and sometimes insidious, is. Tehran's urbanization rate in 1385 was $91 / 34$ percent to 80/92 percent, with growth in 1390 reached $1 / 46$ percent. In the city of Tehran, the rate of 70/98 per cent in 1385 and in $1390,99 / 42 \%$ which is $0 / 72$ percent. The percentage of urbanization in the city of Tehran in 1390, 99/42 percent that has numerous negative effects on biodiversity area.

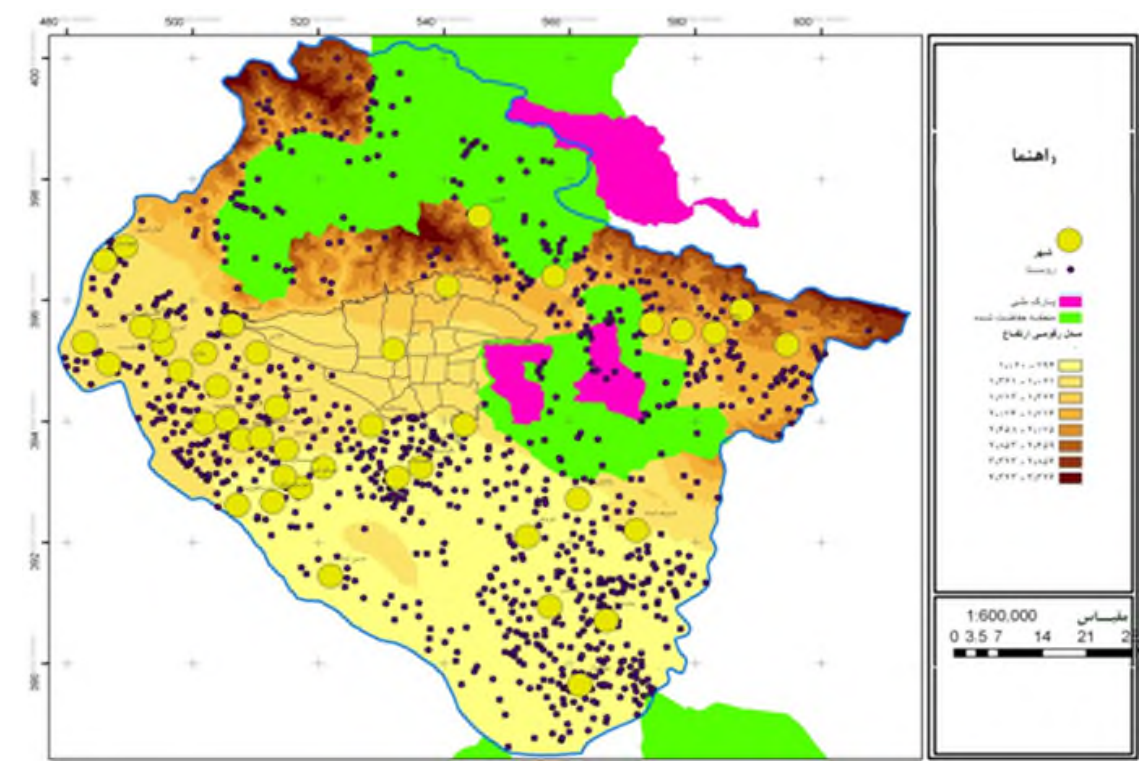

Figure 1: Urban and rural settlements near protected areas in Tehran

\section{Maintain native biodiversity in urban planning and management}

Biodiversity (Biodiversity) a combination of the Greek word meaning life Bios and Latin Diversities there are various means. The diversity of living organisms is called biodiversity. This diversity encompasses all living beings, including plants, animals and other organisms are present in different ecosystems. Natural biodiversity constitutes the foundation of other groups such as the biodiversity of urban biodiversity and agricultural biodiversity and domestication of plants and animals today, over the years the selection, modification and domestication of wild creatures were developed. According to the Association on Biological Diversity (CBD), the diversity among living organisms from all sources including among earthly creatures, marine and other aquatic ecosystems (diversity within species, between species and of ecosystems) as 
"biodiversity" is mentioned. CBD has three main aims include: conservation of biodiversity (ie maintaining security systems of all life on Earth and respect for the powers of the future for human development), sustainable use of ecosystem components (ie providing livelihoods for people without compromising future generations powers), and fair and equitable sharing of benefits arising from the use of genetic resources, is. In a world where we are year to year saw the loss of species, the concept of biodiversity on Earth, it is necessary to protect it. Preserving the rich biodiversity of our planet and the diversity of life forms over millions years emerged as one of the most important tasks of our time is recognized. Loss of species means that the decline of biological heritage for future generations the moral value of an act is wanton. Larger cities and regional land are in fact a continuous set. In fact, a series of regional land base for natural lands within the city itself, but its place has an identity of scale sheriff. Tehran geomorphological and climatic diversity is remarkable is the diversity and ecosystem diversity grounds. Studies, the number of plant species in Tehran from 1308 to 1550 species have been listed. The state of the environment report published in Tehran in 1390 and 1308 the number of plant species as the species. The report also charged that Iran's 194 mammal species, 38 species of mammals, 200 species of reptiles in Iran, 28 species of reptiles, 20 species of amphibians in Iran, two species, 517 bird species in Iran, 136 Iran species and 167 species of fish, 10 species of fish in the region, Tehran. Generally, Tehran has 7 different habitat types below, each of these types has the potential and specific requirements for plant growing and animal species are attracted.

\section{- Mountains and rocky environment of north Tehran}

These habitats, including mountains and rocky areas north of Tehran is higher than 1750 meters above sea level. The main characteristic of this habitat high slope, vegetation cover less than 50 percent, with rock and stone feeder areas above $50 \%$, relatively cold winters and longer than in the urban environment.

\section{- Hills north of East Tehran}

This habitat consists of hilly lands in the North and North East of Tehran. Characterized by a high $90 \%$ range of habitats, including vegetation, gentle slope, altitude between 1,700 and 1,900 meters.

\section{- River environment}

These habitats, including rivers of North and North West of Tehran. The main characteristic of this habitat flow of water and bedrock - it is sandy. Since the source of the rivers from the highlands and is the result of precipitation and melted snow, water is relatively clean and transparent. Pollution of waters caused by human factor is often your garbage into the river shed.

\section{- Wetland and lake environments}

These habitats, including wetlands, stagnant water or environments with slow currents. The main property of habitats, including relatively stagnant water, aqueous solutions containing more than half a meter depth, vegetation and other aquatic plants is required.

\section{- Buildings and the urban environment}

This is a man-made habitats, including buildings and structures. The main characteristic of this habitat is abnormal. Some birds of prey from behind the windows of tall buildings and sometimes use them as resorts. 


\section{- Urban parks and green spaces}

The most diverse habitats habitat for the birds. Parks and greens spaces and suburban many birds are attracted to them. The old park is obviously higher and calmer environment could have expected to find a greater variety.

\section{- Farms south of Tehran}

These habitats, including fields and vegetable plantations of southern Tehran that some of them even moved to the vicinity of residential houses. The habitats are cultivated vegetables, wheat, corn and other agricultural products, suitable habitat and consequently the birds of prey is rodents.

\section{The need to preserve biodiversity}

All species have the inherent right of survival and existence. The integrity of ecological processes Biosphere and its diverse species, land and habitat supports, must be maintained. Cultures of human adaptations to local environments so must have the right to prosperity and sustainability. Sustainability as a fundamental principle in all areas of economic and social development. The need to protect living beings, is for several reasons.

\subsection{The life chain}

Unbelievable chain is vital that the destruction of the living world without punishment, there is even a ring. Animals need plants that can convert solar energy into food. To transfer pollen and fertilize the plants, the animals are in need and survival of animals depends on the survival of the victims.

\subsection{A therapeutic treasures}

Doctors, thousands of plants in the Amazon, India, Southeast Asia and China are traditional ways. Many different medications are especially aquatic animal origin $80 \%$ of the population in developing countries are treated with natural remedies.

\subsection{A large warehouse}

Food and agricultural products we depend on biodiversity. Nature is the great repository of food that has not been used yet. Humans to choose their specialized materials is quite conservative.

\subsection{Mineral for industry}

Starches, sap of some plants, vegetable oils, vegetable or animal fats, is used by all branches of industry are long. Plants such as sugar cane, sugar beet and wheat, green energy hopes are known. In this regard, the Convention on Biological Diversity Tenth Conference of Parties to the Convention, held in 2010 in Aichi, Prfkcher in Nagoya, Japan. Five overall strategic goal is a total includes 20 sub-goal, for 2011 and 2020 were considered and the objectives of the "Aichi Biodiversity Targets" called.

- addressing the causes of loss of biodiversity

- Enter the direct pressures on biodiversity and promote sustainable use

- improve the status of biodiversity by safeguarding ecosystems, species and genetic diversity

- increasing public benefits of biodiversity and ecosystem services

- advance the implementation through participatory planning, knowledge management and capacity building

These strategic goals, 20 targets, which contain more detailed, as was proposed earlier, as they are called, Aichi targets. Goals include:

Raising awareness 2. Inclusion (integration) values of biodiversity 3. Trim incentives (incentive systems) 4. 5. Sustainable production and consumption reduced to half or loss of habitat 6 . 
Sustainable management of marine living resources 7. Agriculture, aquaculture and sustainable forestry 8. 9. Reducing pollution control and prevent the arrival of alien invasive species on ecosystems vulnerable to 11 . 10. Reduced pressure to increase and improve the status of protected areas to preserve genetic diversity 14.13.12. Prevent the extinction of the protection of ecosystems and vital services (required) restoration of ecosystems and increase their flexibility 15. 16. 17. Nagoya protocol enters into force and applicable acceptance of national biodiversity action plans as guidelines (documents) political respect for traditional knowledge 18. 19. Upgrading the level of participation and its application 20. Increasing financial resources.

Years 2011-2020 based on strategic objectives decades under biological diversity is accounted for by the United Nations:

1) Providing a support framework for the implementation of the strategic plan 2011 to 2020 and the Aichi biodiversity targets at the national, regional and international

2) Conducting regional and international organizations

3) Public awareness of biodiversity issues

\section{City Biodiversity Index (CBI)}

The tools available to help cities manage biodiversity. One of the city's biodiversity index tool (CBI), also known as the Singapore Index) is. These and many other initiatives can help to conserve and manage biodiversity in cities. City Biodiversity Index (CBI), Singapore is known as an indicator of biodiversity in cities, a self-assessment tool that encourages cities to monitor and evaluate their progress in maintaining and increasing the biodiversity. More than 50 cities around the world in various stages of testing CBI and provide information for it. The index currently includes 25 indicators in three components: native biodiversity, ecosystem services provided by biodiversity and biodiversity management. Index (CBI) is used as a self-assessment tool for cities and their biodiversity conservation efforts monitors' progress. It consists of two parts: the first, "City View" provides background information in the second, 25 indicators that measure native biodiversity in urban areas, biodiversity, ecosystem services and biodiversity management provides. Each indicator is assigned between zero and four points.

\subsection{Methodology}

Biodiversity (CBI) in the two components of biological diversity native to the city and divided biodiversity monitoring and management. Components of biological diversity native to the city includes the following indicators:

- $-\%$ of natural and semi-natural areas

- Diversity of ecosystems

- Measuring fragmented disruption

- Biodiversity in residential areas

- The number of endemic species

- protected areas

- The proportion of native species to non-native species

- Services freshwater

- Carbon storage

- Educational services and Recreation

- Monitoring and management of biodiversity components include the following indicators:

- The budget allocated to biodiversity projects

- The number of programs and projects for biodiversity that is organized every year by city 
- Laws, regulations, and policies

- Organizational capacity

- Partnership

- Education and awareness

\subsection{Reasons for choosing the indicators and how to calculate}

\subsubsection{Percent natural and semi-natural areas}

In this index, natural or semi-natural ecosystems that are largely disturbed areas and manmade shelters many species are compared. Thus, by comparing the ratio of the area of natural areas in the urban area of biodiversity richness index is obtained.

\subsubsection{Diversity of ecosystems}

The number of existing ecosystems in the ecological niche of a good indicator of the diversity of fauna and flora indigenous to the city. Since the different ecosystems in different geographical areas can be seen. Any type of land and water ecosystems such as forests, swamps and freshwater wetlands, meadow, natural, rivers, streams, lakes, mud flats, dunes and ... can be used in the calculation of the index.

\subsubsection{Measuring fragmentation disruption}

Fragmentation of natural habitats is one of the most immediate threats to the sustainability of urban biodiversity. Therefore, the selection of these indicators can be drawn the change habitats future. There are several ways to measure the level of habitat fragmentation:

- The average size of patches

- The distance between spots

\subsubsection{Biodiversity in residential areas}

Now we know that no minimum amount of natural forms and areas of green space in the city. But in these areas various forms such as birds such as swallows that nest of biodiversity itself under the roof of their building, and the plants that grow on buildings there. Biodiversity in different residential areas with each other are different. By increasing the effects of habitat and natural forms in residential areas can be improved biodiversity.

\subsubsection{The number of endemic species}

Taxonomic groups that have been widely studied, including plants, birds and butterflies are the core group of these indicators are considered. To achieve the desired goals Cities could taxonomic groups such as mammals, reflecting favorable terms to choose their biodiversity.

\subsubsection{Protected areas}

Natural protected areas or safe cities represents a commitment to the protection of biodiversity. Hence, the natural protected areas or secure as an important indicator.

\subsection{7. the proportion of native species to non-native species}

Non-native species through competition with native species, threatening their survival. Since the city is safe from the influence of non-native species, measuring this parameter specifies the status of threatened species and the ecosystem. To measure this indicator is calculated as the ratio of non-native species to species. 


\subsubsection{Services freshwaters}

Fresh water is one of the essential needs of human survival. Good forest cover in a watershed area in addition to providing water treatment and clean water cities. The index is calculated in the cost of water treatment.

\subsubsection{Carbon storage}

In the process of photosynthesis in plants, they trap carbon dioxide. Therefore, the carbon emitted from human activities in the holds. The total number of trees (natural and planted) in a city, indirect measurement of carbon sequestration provided by the biodiversity of the flora of the city.

\subsubsection{Education and recreation services}

Biodiversity, educational and recreational services provides valuable to citizens. The essential need for mental health services and substance of its citizens.

\subsubsection{1. the budget allocated to biodiversity projects}

The first two sections, biodiversity and ecosystem protection in the city to evaluate. This indicator programs and projects that maintain and increase biodiversity in cities is to evaluate. The calculations should include municipal budget or manpower cities, the cost of the project.

\subsubsection{2. the number of programs and projects for biodiversity that is organized every year by city \\ Projects and programs, including those relating to the protection of plants, birds, butterflies, species restoration, biodiversity assessment and biodiversity is increased.}

\subsubsection{Laws, regulations, and policies}

To ensure the proper management should be a policy. To facilitate the operationalization of policies, laws and regulations should be in place. This section explores the policies, laws and regulations related to biodiversity and explores whether these rules are consistent with strategies and national action plans. Most plans include plant protection, forest biodiversity, global classification plan, schedule of non-native and invasive species, marine biodiversity conservation, protected areas and so on.

\subsubsection{Organizational capacity}

There are organizations for the effective implementation of projects and programs is necessary. Therefore there are centers of biodiversity and its associated organizations strongly increases the conservation of biodiversity in the city. Some of these essential organizations including the Center for Biological Diversity, herbarium, zoological centers, museums, botanic gardens and insectarium and more. Some of biodiversity are the same width. Therefore, interorganizational cooperation are included. Interagency coordination and biodiversity conservation is an important index to measure success. Especially in cities with high density.

\subsubsection{Partnerships}

There are two factors for this indicator. The first assessment of the existence of formal and informal consultations. Second Assessment of formal and informal cooperation. As with all matters related to biodiversity by an organization or office is impossible, therefore, to participate and assist all levels of people, and this includes city officials, citizens, private sector, nongovernmental organizations, people and more. 


\subsubsection{Education and awareness}

Training is done in two ways: formal and non-formal schools or with exposure to educational materials. These indicators consider two aspects. For example, formal education and information. Students from recreational use by an ecosystem is one of the measures of the measure. Two other measures to educate and raise awareness is raised.

1) Does biodiversity is included in the curriculum?

2) How many public information is carried in?

Most cities do not have the power to intervene in the educational materials. The juxtaposition of the index results in opportunities for education authorities is to communicate with city officials to biodiversity related courses in grades pre-school, primary, secondary and high schools be taught. The number of programs over the years in terms of information and diversity of information reflects the city manager to increase efforts to preserve biodiversity. As noted, the score for each indicator considered is between 0 and 4, according to 25 indicators specified by the total score is between 0 and 100. After analyzing the data, the following table summarizes the status of biodiversity in the city:

Table 1: Status of Biodiversity

\begin{tabular}{|c|c|}
\hline Condition & The amount of \\
\hline Excellent & $100-91$ \\
\hline very well & $90-71$ \\
\hline Good & $70-56$ \\
\hline Average & $55-41$ \\
\hline Weak & $40-21$ \\
\hline very weak & $20-0$ \\
\hline
\end{tabular}

\section{Discussion and Conclusion}

Tehran due to its geographical location (proximity to the Alborz mountains and the desert) has a potential richness of biodiversity and climate conditions, but due to unregulated construction, air pollution and water resources, convert users and cut old groves of trees, climate change and lack of attention to the high value of its massive trove of biodiversity, habitats and destruction in these cities is changing. Among the important driving forces in Tehran and notable biodiversity loss, increasing population and consequent increased pressure on the environment and biodiversity, the most important challenge in this sector, population growth in the settlements around the city of Tehran in urban collection. Which indicates the dominance of urban life that has many negative effects on biodiversity of the region. Tehran is one of the main pressures on biodiversity, land cover change and become open and green spaces and roads, especially highways are built. As well as entry into the various sectors of environmental pollution (air, water, soil) as well as air emissions and waves, leading to the loss of biodiversity is in Tehran. Log in living organisms infect the body through breathing, feeding and entry into the food chain, leading to deaths and migration of species is critical of Tehran Water harvesting, without any regard to environmental issues has led to the destruction of river ecosystems in catchment basins associated with Tehran. The climate change through changes in habitat (extent and quality) and finally undesirable for sensitive species, impacts on biodiversity. The weather 
has been warmer the temperature in Tehran. This can lead to increased desertification and the loss of habitat to be more moderate areas. River valleys in the city play an important role in the city's biodiversity. Tehran has 13 endemic plant species. Large mammals and important natural habitats such as national parks and protected area Jajrood Sorkhehesar and Khojir are present and outside of these areas, species such as foxes and rabbits and can only be the common species used in urban environments. National and international organizations as well as from the standpoint of environmental protection, a total of 11 species are vulnerable in Tehran. The effects of biodiversity loss can disrupt the normal structure and function of ecosystems into two main sections and their associated organisms divided. Tehran landscape structure of disorders caused by the destruction of natural ecosystems and convert them to land is made. Functional disorders include dysfunction corridors, climate change and land cover caused by the conversion of native species is the loss of population. Index (CBI) cities to accomplish your goals through three mechanisms related to biodiversity, which is critical to a positive outcome policies will help. All this index cannot be used in decision-making and planning in Tehran; it can also help in the allocation of resources and prioritization of projects Tehran metropolitan city. Some of the parameters can be the basis for calculating the economic value of biodiversity and ecosystem services are the city.

So to preserve and restore biodiversity Tehran, in this study, two general strategies have been proposed.

- Assessment of biodiversity in Tehran using the CBI index

- Use of measuring the state of biodiversity in urban planning and management to restore ecological services and thus reduce environmental pollution and health of citizens

\section{References}

1. Pryor, c. (1392). Coherent framework for strategic environmental assessment of urban development plans based on the idea of resiliency and principles of urban ecology. Ph.D. Thesis. School environment. University of Tehran.

2. Aliana, b. (1387). Tehran climate. Environmental challenges and strategies of Tehran Metropolis (pp. 19-36). Tehran: Tehran Urban Planning \& Research Center.

3. The State of Environment in Tehran (SOE) (86-1377), (1390). Center of Tehran Urban Planning.

4. EEA. "Integrated Environmental Assessment of Biodiversity." 2013. www.eea.europa.eu.

5. Impervious surface coverage: Emergence of a key environmental Indi catoramerican planning association 1996243-258

6. European Environment Agency \& Swiss Federal Office for the Environment (2011): Landscape fragmentation in Europe. Joint EEA-FOEN report. Authors: J.A.G. Jaeger, T. Soukup, L.F. Madriñán, C. Schwick, F. Kienast. EEA Report No 2/2011, ISSN 1725-9177, ISBN 978- 92-9213-215-6, doi: 10.2800/78322. Luxembourg, Publications Office of the European Union. 87 pp.

7. Taylor, P.D., Fahrig, L., Henein, K., and Merriam, G. (1993): Connectivity is a vital element of landscape structure. Oikos, vol. 28, issue 3, pp. 571-573.

8. Cities and biodiversity outlook(CBO)-action and policy.No 1, (2014)

9. Current concervation journal, vol 8, issue 1(2014) 
Bulletin de la Société Royale des Sciences de Liège, Vol. 85, 2016, p. 1730 - 1739

10. Thomas elmquist, michail fragtias, Julie goodness- Urbanization biodiversity and ecosystem services: challenges and opportunities (2013)

11. User's manual on the Singapore index on cities' biodiversity (2014) 